\title{
Examining the Efficacy of Personal Response Devices in Army Training
}

\author{
Angelina Hill \\ College of the Redwoods, \\ Eureka, California, USA
}

Angelina-Hill@redwoods.edu

\author{
Bea Babbitt \\ University of Nevada, \\ Las Vegas, Nevada, USA
}

Bea.Babbitt@unlv.edu

\section{Executive Summary}

Benefits of personal response devices (PRDs) have been demonstrated in a variety of settings and disciplines in higher education. This study looked outside of higher education to investigate the efficacy of PRDs in an Army training course in terms of trainee performance, engagement, and satisfaction. Instructors were also surveyed to determine their perceptions of the impact of PRDs on student learning and engagement. Participant trainees reported that they were more engaged and had a better understanding of how well they understood the material because of the PRDs. Participants who had previously taken the course without PRDs reported a preference for the training with PRDs in terms of being more engaged, learning more, and enjoying the course more. No improvement in performance was detected when comparing final exam scores in these courses to prior courses that did not use PRDs. Instructors appeared to see benefits afforded to their students, but they also found the course more challenging to teach, highlighting the need for adequate training to use the new technology, and care taken to developing effective questions.

Keywords: personal response devices, clickers, army, military, enhanced training.

\section{Introduction}

Personal Response Devices (PRDs) have demonstrated success in terms of engagement (e.g., Caldwell, 2007; Hall, Collier, Thomas, \& Hilgers, 2005) student satisfaction (e.g., Byrd, Coleman, \& Werneth, 2004; Johnson, 2005; Lowery, 2005), and performance (e.g., Edens, 2009; Poulis, Massen, Robens \& Gilbert, 1998; Ribbens, 2007) in a variety of venues. In the college classroom, PRDs have been shown to be beneficial in a variety of disciplines. The greatest extent of research has been in the science arena, but research studies have also been conducted in the fields of medicine, mathematics, business, social science, and more (Kay \& LeSage, 2009). PRD use is also widespread at the K-12 level. Although research is much more comprehensive in higher education, a survey of K-12 teachers provided evidence that they use many of the same techniques used to make PRDs effective in higher education (Penuel, Boscardin, Masyn, \& Crawford,

Material published as part of this publication, either on-line or in print, is copyrighted by the Informing Science Institute. Permission to make digital or paper copy of part or all of these works for personal or classroom use is granted without fee provided that the copies are not made or distributed for profit or commercial advantage AND that copies 1) bear this notice in full and 2) give the full citation on the first page. It is permissible to abstract these works so long as credit is given. To copy in all other cases or to republish or to post on a server or to redistribute to lists requires specific permission and payment of a fee. Contact Publisher@,InformingScience.org to request redistribution permission.
2007).

Research on the impact of PRDs has grown substantially in the 2000s, but this growth has not been evenly distributed across educational settings. A recent review of the literature by Kay and LeSage (2009) noted a lack of research outside of higher education and ics/science-based courses, and that conducting this research would help provide a 
fuller understanding of the impact of PRDs. The current study was performed to see if the effectiveness of PRDs will extend to a structured educational setting outside of higher education: an Army training course. PRDs are currently used in a variety of military trainings, such as in Army JROTC instruction (Worldwide Instructional Design System, 2010), Navy Submarine Training, and Air Force Medical Training (eInstruction, 2011). However, evidence of effectiveness in military settings is not readily available in the published literature.

\section{Research Context}

The Army training course under investigation (Combat Lifesaver training) is given to active and reserve Army personnel so that they can provide emergency medical care as non-medic soldiers in combat. Soldiers are instructed to treat and stabilize injuries including blast injury, amputation, severe bleeding, and penetrating chest injuries. Trainees use PRDs, a small handheld electronic device, to respond to questions embedded in presentation materials. The number or percentage of responses for each response option are displayed immediately and usually graphically. This provides immediate feedback which is beneficial to students (Edens, 2009), providing knowledge of how well they understand compared to their peers (Stuart, Brown, \& Draper, 2004). Given that Combat Lifesaver training takes place during a condensed one-week period, a large amount of material is covered each day, making the use of daily/immediate feedback seem highly beneficial.

Other advantages of PRDs depend on the effectiveness of the questions, the climate in the classroom, and the instructor. PRDs have been shown to be more beneficial when questions promote discussion (DeBourgh, 2008) and deep thinking, as opposed to retrieval of facts (MacGeorge et al., 2008). Only a small amount of the material covered in Combat Lifesaver training can be learned easily and through basic memorization. For example, soldiers must be able to quickly determine what course of action to take in a combat situation when faced with a host of factors that weigh into their decision. Higher-level questions that focus on critical concepts, when asked with PRDs, should create time for trainees to reflect on the best course of action.

PRDs have also been shown to be more effective when instructors are aware of student performance and adjust the material they emphasize accordingly (Oerman \& Gaberson, 2006). Trainee performance typically varies widely in a Combat Lifesaver training course. A typical course has trainees with varying rank, and because the course can be repeated numerous times some trainees have more direct exposure to the material than others. This diversity makes it appear very beneficial for instructors to quickly assess performance so that they can tailor each class.

Similar to the variations in classroom size across higher education's colleges and universities, the Combat Lifesaver training size also varies based on the training site and available facilities. The always-changing military deployment schedule necessitates instructional techniques that are not dependent on classroom size. Most of the benefits of PRDs have been observed in large classrooms (Boyle, Nicol, Hamilton, \& Dempster, 2001; Nicol \& Boyle, 2003), where personal feedback and interaction with the instructor is more challenging. Smaller classrooms, however, have also been shown to benefit (e.g., Herreid, 2006). Although small classes make student discussion and engagement more feasible, PRDs can further motivate students to be involved (Lea, 2008). Students benefit from defending their answers to their peers, clarifying points of uncertainty or misunderstanding, and increasing their critical thinking abilities (Frederickson \& Ames, 2009).

At a surface level, it appears that the effects of PRDs that have been documented in higher education should extend to Combat Casualty training. At the most general level, PRDs enhance student engagement, which promotes active learning (Hall et al., 2005). A more active learning environment leads to more engaged students and is believed to enhance student learning (Chickering \& Gamson, 1987). Greater engagement has been shown when all students respond to questions posed by the instructor, rather than just a few who typically respond (Frederickson \& Ames, 
2009). In contrast to many advanced Army laboratory training environments, the lecture environment for Combat Casualty training has typically been passive. It was suspected that training would greatly benefit from an environment that promoted active engagement. The following study looks at the impact of PRDs in an Army training course by investigating their impact on student performance, engagement, and satisfaction. Benefits and challenges to instructors were also investigated.

\section{Method}

\section{Participants}

A sample of 117 soldiers taking a Combat Lifesaver course at a National Guard Training Center participated in the study. Sixty-five of the soldiers were taking the Combat Lifesaver course for the first time. Fifty-two of the soldiers were repeating the course. Thirty-four of the repeaters were taking the course for the second time, and the remaining 18 had taken the course between three to five times before.

The sample was obtained from three Combat Lifesaver training classes. Two were offered in May of 2010, each of which had 50 trainees. The third class was offered in August of 2010 and had seventeen trainees.

The instructors of these three training classes also participated in the study. All classes were team taught with two instructors. Instructors varied by class, with the exception of one instructor who took part in two classes. This resulted in five different instructors. All were experienced in teaching the Combat Lifesaver training course.

\section{Materials and Procedure}

Instructors involved in the study had previously taught the course without PRDs using a PowerPoint presentation that was broken into ten lessons. As part of the study, instructors used a revised ten lesson PowerPoint presentation with an average of approximately eight questions per lesson. The questions were developed with curriculum experts from the Army National Guard Medical Operations Instructional Team for response using PRDs. The PowerPoint presentation was also reduced in length to focus on content most valuable to the instructors and curriculum experts and to allow for time to devote to the PRD questions. Instructors delivered the presentation using the CPS Pulse student response system sold by the company eInstruction. This system enabled questions to be incorporated directly into the PowerPoint presentation, and instructors provided aggregate class results in chart form immediately following student responses. All soldiers were provided with the CPS Pulse response devices during the lectures.

Participants completed the Combat Lifesaver course over a five-day period. Each lecture was followed by a lab and simulation exercise, the content of which was not altered during the study. Following the complete delivery of the lecture part of the course, a questionnaire was given to each of the soldiers. This questionnaire, which is provided in Appendix A, asked soldiers about their satisfaction, engagement, and perceived amount of learning in the training. The questions made specific reference to their use of the PRD, which instructors referred to as "clickers." Participants who had taken the course in the past were also asked questions related to their preference for this new "clicker" version of the training vs. the "non-clicker" version.

A questionnaire was also given to instructors at the end of each course. This questionnaire, provided in Appendix B, asked instructors about their preferences regarding their teaching of the new "clicker" version vs. the "non-clicker" version, as well as how they perceived students to benefit from the new version. 
Performance was also evaluated by comparing results of the standard exam that accompanies all Combat Lifesaver courses. This exam is taken at the completion of the course and must be completed with a successful pass rate of 70 percent in order for trainees to receive Combat Lifesaver certification. The exam consisted of 40 multiple-choice questions that are directly related to the content covered in lecture. The exam was not altered in any way from previous trainings for this study. Exam questions differed from the questions that were included in the PowerPoint presentation to be answered using the PRDs, but they did assess the same content.

\section{Results}

\section{Trainee Satisfaction and Engagement Ratings}

Survey responses from soldiers were analyzed using a chi-square test of goodness of fit to determine whether solders showed agreement to positive aspects of the training course and to the incorporation of PRDs. The results for each survey item are presented in Table 1. All questions resulted in the soldiers showing significant agreement to the positive aspects of the course and use of PRDs. When asked specifically about the use of the PRDs, participants showed significant agreement (89.3\% strongly or somewhat agreed) that the PRDs made the class more engaging, $\chi^{2}$ $(1, \mathrm{~N}=112)=69.14, \mathrm{p}<.001, \omega=.79$. Participants also agreed $(87.6 \%$ strongly or somewhat agreed) that the PRDs made them better aware of how well they understood the material, $\chi^{2}(1, \mathrm{~N}$ $=113)=63.94, \mathrm{p}<.001, \omega=.75$.

\begin{tabular}{|l|c|c|c|c|c|}
\hline \multicolumn{6}{|c|}{ Table 1: Analysis of Soldier's Perceptions of Enhanced Lecture } \\
\hline \multicolumn{1}{|c|}{ Survey Question } & \% Satisfied & N & $\chi^{2}$ & $\omega$ & $p$-value \\
\hline $\begin{array}{l}\text { Training exceeded my } \\
\text { expectations }\end{array}$ & 86.8 & 114 & 61.895 & 0.737 & $<.001$ \\
\hline $\begin{array}{l}\text { Confident I could ap- } \\
\text { ply learned skills in } \\
\text { combat }\end{array}$ & 93.8 & 112 & 85.75 & 0.875 & $<.001$ \\
\hline $\begin{array}{l}\text { Found training course } \\
\text { engaging }\end{array}$ & 95.6 & 113 & 93.885 & 0.912 & $<.001$ \\
\hline $\begin{array}{l}\text { Clickers made class } \\
\text { more engaging }\end{array}$ & 89.3 & 112 & 69.143 & 0.786 & $<.001$ \\
\hline $\begin{array}{l}\text { Clickers made me bet- } \\
\text { ter aware of how well } \\
\text { I understood materials }\end{array}$ & 87.6 & 113 & 63.938 & 0.752 & $<.001$ \\
\hline $\begin{array}{l}\text { I could easily follow } \\
\text { along with the text- } \\
\text { book }\end{array}$ & 80.5 & 113 & 42.133 & 0.611 & $<.001$ \\
\hline
\end{tabular}

An independent-samples t-test revealed no significant differences across participants who were repeating the course vs. first-timers in terms of PRDs making the class more engaging, $\mathrm{t}(110)=$ $1.00, \mathrm{p}=.339$, or in terms of PRDs making them better aware of how well they understood the material, $\mathrm{t}(111)=.838, \mathrm{p}=.414$. 
Questions asking participants who were repeating the course to rate their preference for the version of the course with vs. without PRDs were also evaluated using a chi-square test of goodness of fit to determine whether solders showed a preference for the PRD version. The results for each survey item are presented in Table 2 . This table shows that all questions resulted in a significant preference for the version of the course that includes PRDs. Over eighty percent $(82.4 \%)$ indicated that they would rather repeat the clicker version of the course, and the same percentage indicated that they were more engaged in this version of the course. An even higher percentage $(84.3 \%)$ indicated that they enjoyed the PRD version more than prior versions. Participants also gave a significant preference for having learned more in the PRD version $(72.5 \%)$, but this preference resulted in a smaller effect size $\left(\chi^{2}(1, \mathrm{~N}=51)=10.37, \mathrm{p}<.001, \omega=.45\right)$ than did questions related to engagement and enjoyment.

\begin{tabular}{|c|c|c|c|c|c|}
\hline $\begin{array}{l}\text { Clicker to non-clicker } \\
\text { training Questions }\end{array}$ & $\begin{array}{l}\% \text { Indicating } \\
\text { Preference } \\
\text { (above neutral) }\end{array}$ & $\mathbf{N}$ & $\chi^{2}$ & $\omega$ & $p$-value \\
\hline Repeat clicker version & 82.4 & 51 & 21.353 & 0.647 & $<.001$ \\
\hline $\begin{array}{l}\text { More engaged in clicker ver- } \\
\text { sion }\end{array}$ & 82.4 & 51 & 21.353 & 0.647 & $<.001$ \\
\hline $\begin{array}{l}\text { Learned more in clicker ver- } \\
\text { sion }\end{array}$ & 72.5 & 51 & 10.373 & 0.451 & $<.001$ \\
\hline Enjoyed clicker version & 84.3 & 51 & 24.02 & 0.686 & $<.001$ \\
\hline $\begin{array}{l}\text { Had easier time following } \\
\text { along with book in this ver- } \\
\text { sion }\end{array}$ & 62.6 & 51 & 3.314 & 0.255 & 0.069 \\
\hline
\end{tabular}

\section{Qualitative Feedback from Trainees}

Participants were asked to explain in what ways, if any, the response clickers helped them learn the material. The majority of responses fell into three major categories of perceived benefits from (1) various types of interactivity, (2) reinforcement of material, and (3) ability to participate with anonymity. Almost half of all soldiers (48.7\%) remarked on various ways that the PRDs made the course more interactive. The answer given most frequently was that answering the questions kept them more engaged/motivated. Almost a quarter of respondents $(22.22 \%)$ remarked on positive ways the PRDs reinforced the material. This included benefits from thinking about and forming a response to the question that is followed by immediate feedback, as well as how the discussion with the instructor following the answer reinforced their understanding. Finally, a handful of participants $(6.84 \%)$ remarked on the benefits of the anonymous environment that the PRDs promoted, allowing them to participate when they might not otherwise, without the influence or worry of getting the answer incorrect in front of peers.

Participants were also asked to write about how they would improve the use of clickers in the training class. Nearly sixty percent of participants $(59.85 \%)$ remarked on program glitches such as computer freezes and clickers not responding, making up $70 \%$ of all the comments provided. A handful of unique responses, such as utilizing timers for self-read portions and incorporating 
short videos to maximize interactivity further demonstrated the participants' engagement with the training.

\section{Performance}

The final exam performance of participants in the study was compared to the performance of all trainees having taken a course without the use of PRDs during the previous year at the same National Guard Training Center. Scores from 1,065 trainees were included in this cohort. An independent-samples t-test revealed no significant difference between the exam scores of participants in the PRD classes $(\mathrm{M}=87.28, \mathrm{SD}=6.59)$ with all trainees who took the non-PRD course the prior year $(\mathrm{M}=88.43, \mathrm{SD}=7.22), \mathrm{t}(1180)=1.54, \mathrm{p}=.124, \mathrm{~d}=0.16$.

\section{Instructor Perceptions}

Instructors, all having taught the course prior to incorporating PRDs, provided ratings to questions comparing the course with vs. without the use of PRDs. Only five instructors participated in the study, which meant that too few responses were collected to conduct any inferential statistics on their preference for the use of PRDs. However, no instructors indicated a clear preference for the training that used PRDs. Many of the instructors had a slight preference (between clicker and no preference) for the course with PRDs in terms of teaching that version again, being more engaged, and believing that the soldiers learned more. None of the instructors, however, favored the PRD training (even between PRD and no preference) in terms of it being easier to teach.

Instructors were also asked a series of open-ended questions about the enhanced course. The main benefits they saw from the clickers was that they made the trainees more attentive/alert and that the trainee feedback was an asset so that they could identify topics needing further discussion. Three of the five instructors also commented that a main benefit to trainees was the discussion that was elicited following a question. When asked what changes they would make if they were to continue using this format, the main suggestions were related to the questions in terms of revisions to some of the questions, moving questions to the end of the lecture, and trimming the number of questions to reduce the impact on lecture time.

\section{Discussion}

Trainees and instructors both indicated that the PRDs enhanced engagement in the classroom. Participant trainees also perceived themselves as learning more, but this was not supported by increased exam performance. The participants' performance scores, however, were very high prior to the use of PRDs. It is likely that a ceiling effect may have made it difficult to detect increased performance due to the PRDs. Testing, in addition to the final exam, wasn't feasible in this training, but future performance measures developed for the sole purpose of measuring PRD effectiveness are needed to better understand PRDs' impact on performance.

Participants who had taken the same training in the past but without PRDs indicated that they preferred the course with PRDs. The choice wasn't as clear for the instructors. Instructors appeared to see the engagement and learning benefits afforded to their students, but they also reported that PRDs made the course more difficult to teach. Three issues appeared to be central to this difficulty: technical problems, classroom management, and required changes in pedagogy.

Instructors needed to become familiar with new software to implement the PRDs. That software was sometimes incompatible with other technology used, resulting in program freezes. Clearly, instructors will find the course difficult to teach while experiencing technical problems, highlighting the importance of substantial training to make them comfortable using the new technology.

Participants also needed adequate training to operate the new technology. Instructors were given training to use PRDs, but none of the instructors were experts, and most experienced technical 
difficulties during the trainings. The extent of technical difficulties was probably more prevalent in these trainings than in higher education settings because of the high level of computer security necessary at a National Guard Training Center. Many of the participants noted the technical difficulties when asked how to improve the training. But even with these glitches, trainees still showed a clear preference for the inclusion of PRDs.

A second concern of the instructors was how they could discuss the questions effectively without increasing lecture time. The discussion elicited by the questions, which is crucial to the effectiveness of the PRDs, created timing and class management issues for some instructors. The discussions appeared to take increased instructional time, and the transition back to the lecture was a challenge for some instructors. Such issues would likely be eliminated or greatly reduced with additional training and experience using the PRDs. With experience, instructors should recognize that clickers eliminate the need to discuss topics that are well understood and allow more time to discuss topics where misunderstandings are evidenced (Anderson, Healy, Kole, \& Bourne 2011). Smooth transitions back to the lecture will occur as instructors establish standard classroom protocols for PRD use.

A third instructor concern related to question wording. Some of the textbook derived questions were too simple to evoke meaningful discussion. The research team collaborated with the instructors to improve this aspect of the training, but more work in this area appears to be needed.

Finally, the effective use of PRDs requires that instructors capitalize on the learning that takes place when students actively interact with content. The discussions that take place following PRD use are crucial to enhancing understanding. Instructors who have not used this approach will need extensive training regarding the pedagogy behind effective PRD use.

\section{Conclusion}

Overall, the use of PRDs made the training class a more engaging and enjoyable setting for trainees. However, instructors must invest time to comfortably operate the software and to adjust to a different way of teaching. This makes it important that instructors are sufficiently motivated to use the PRDs, and this can be done through proper pedagogical training, and by providing suffi-

cient experience operating the software. Under these circumstances, it appears that PRDs can be a valuable addition to Army training.

\section{References}

Anderson, L. S., Healy, A. F., Kole, J. A., \& Bourne, L. E. (2011). Conserving time in the classroom: The clicker technique. Quarterly Journal of Experimental Psychology, 64(8), 1457-1462.

Boyle, J., Nicol, D., Hamilton, B., \& Dempster, B. (2001, August). The use of classroom feedback systems to enable active learning in large engineering mechanics classes. Paper presented at the International Conference on Engineering Education, Oslo, Norway.

Byrd, G. G., Coleman, S., \& Werneth, C. (2004). Exploring the universe together with and without a classroom performance system in astronomy: 10 cooperative quizzes. The Astronomy Education Review, $3(1), 26-30$.

Caldwell, J. E. (2007). Clickers in the large classroom: Current research and best-practice tips. Life Sciences Education, 6(1), 9-20.

Chickering, A. W., \& Gamson, Z. (1987). Seven principles for good practice in undergraduate education. AAHE Bulletin, 40(7), 3-7.

DeBourgh, G. A. (2008). Use of classroom "clickers" to promote acquisition of advanced reasoning skills. Nurse Education in Practice, 8, 76-87. 
Edens, K. M. (2009). The interaction of pedagogical approach, gender, self-regulation, and goal orientation using student response system technology. Journal of Research on Technology in Education, 41(2), 161-177.

eInstruction (2011). Military and Government Training. Retrieved September 5, 2011 from http://www.einstruction.com/solutions/federal-government-military-and corporate/military-andgovernment-training

Frederickson, E. E., \& Ames, M. (2009). Can a \$30 piece of plastic improve learning? An evaluation of personal response systems in large classroom settings. Retrieved from http://net.educause.edu/ir/library/pdf/csd2690.pdf

Hall, H. R., Collier, L. H., Thomas, L. M., \& Hilgers, G. M. (2005). A student response system for increasing engagement, motivation, and learning in high enrollment lectures. Retrieved September 5, 2011 from http://lite.mst.edu/media/research/ctel/documents/hall_et_al_srs_amcis_proceedings.pdf

Herreid, C.F. (2006). "Clicker cases: Introducing case study teaching into large classrooms. Journal of College Science Teaching, 36 (2), 43-47.

Johnson, J. T. (2005). Creating learner-centered classrooms: Use of an audience response system in pediatric dentistry education. Journal of Dental Education, 69(3), 378-381.

Kay, R. H. \& LeSage, A. (2009). Examining the benefits and challenges of using audience response systems: A review of the literature. Computer \& Education, 53(3), 819-827.

Lea, B. (2008). Clicker adoption in a small class. Decision Line, July 2008, 7-11.

Lowery, C. R. (2005). Teaching and learning with interactive student response systems: A comparison of commercial products in higher-education market. Retrieved September 5, 2011 from http://people.uncw.edu/lowery/SWSSA\%20ms.pdf

MacGeorge, E. L., Homan, S. R., Dunning Jr., J, B., Elmore, D., Bodie, G. D., Khichadia, S., . . Geddes, B. (2008). Student evaluation of audience response technology in large lecture classes. Educational Technology Research and Development, 56, 125-145.

Nicol, D. J., \& Boyle, J. T. (2003). Peer instruction versus class-wide discussion in large classes: A comparison of two interaction methods in the wired classroom. Studies in Higher Education 28, 458-473.

Oermann, M. H., \& Gaberson, K. B. (2006). Evaluation and testing in nursing education (2nd ed.). New York: Springer Publishing Company.

Penuel, W. R., Boscardin, C. K., Masyn, K., \& Crawford, V. M. (2007). Teaching with student response systems in elementary and secondary education settings: A survey study. Educational Technology, Research and Development, 55(4), 315-346.

Poulis, C., Massen, C., Robens, E., \& Gilbert, M. (1998). Physics learning with audience paced feedback. American Journal of Physics, 66, 439-441.

Ribbens, E. (2007). Why I like personal response systems. Journal of College Science Teaching, 37(2), 6062.

Stuart, S. A. J., Brown, M. I., \& Draper, S. W. (2004). Using an electronic voting system in logic lectures: One practitioner's application. Journal of Computer Assisted Learning, 20(2), 95-102.

Worldwide Instructional Design System. (2010). Army JROTC's 21st Century Curriculum. WIDS wire, Fall, 6-9. Retrieved from http://www.wids.org/Portals/0/PDF_Docs/Army_JROTC_Curric_Debuts.pdf 


\section{Appendix A: Questions for Trainees}

\section{Section 1}

Please complete this section if this is NOT the first time you have taken this training course. Skip to Section 2 if this was your first time.

1) How many times have you taken this training (including this course)?

2) Circle the number that best reflects whether, if given the choice, you would prefer to repeat the instructional portion of this course in the clicker or non-clicker format.

The clicker version refers to the format of the training that you just completed that included the use of a personal response clicker. The non-clicker version refers to training that you had in the past that did not use the personal response clickers.

$\begin{array}{lllll}1 & 2 & 3 & 4 & 5\end{array}$

I would rather repeat the clicker version of training

12

I was more engaged in the clicker version of training

$1 \quad 2$

I learned more in the clicker version of training 12

I enjoyed the clicker version of training
I have no preference 3

I have no preference

3

I have no preference

3

I have no preference
I would rather repeat the non-clicker version training

5

I was more engaged in the non-clicker version

5

I learned more in the non-clicker version

5

I enjoyed the non-clicker version of training

Please write your answers to the following questions in the space provided.

4) Which lesson, if any, was most improved in the clicker version? Please explain.

\section{Section 2}

Use the following scale to indicate how much you agree with each of the statements that follow. This is for everyone to complete.
1
2
3
4
Neutral Somewhat disagree
Strongly disagree

Strongly agree Somewhat agree

This training exceeded my expectations. $1 \quad 2 \quad \begin{array}{llll}1 & 2 & 3 & 4\end{array}$

I am confident that I could successfully use the skills I've learned in combat.

$\begin{array}{lllll}1 & 2 & 3 & 4 & 5\end{array}$

$\begin{array}{lllllll}\text { I found this training course engaging. } & 1 & 2 & 3 & 4 & 5\end{array}$ 
The use of personal response clickers made the class more engaging.

$$
\begin{array}{lllll}
1 & 2 & 3 & 4 & 5
\end{array}
$$

The use of personal response clickers made me better aware of how well I understood class material.

$$
\begin{array}{lllll}
1 & 2 & 3 & 4 & 5
\end{array}
$$

Please write your answers to the following questions in the space provided.

1) In what ways, if any, did the response clickers help you learn the material?

2) How would you improve the use of response clickers in this training class?

\section{Appendix B: Questions for Instructors}

1) Circle the number that best reflects whether, if given the choice, you would prefer to repeat the instructional portion of this course in the clicker or non-clicker format.

The clicker version refers to the format of the training that you just completed that included the use of a personal response clickers. The non-clicker version refers to training that you had in the past that did not use the personal response clickers.

1

I would rather teach the clicker version of training

$$
12
$$

I was more engaged teaching the clicker version of training

he

\section{3}

I have no preference
4 I would rather teach the non-clicker version training
1
2

I think the soldiers learned more

in the clicker version of training I have no preference
I enjoyed teaching the

clicker version of training

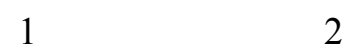

2

The course was easier to Teach

I have no preference

4

5 I was more engaged teaching the non-clicker version

Please write your answers to the following questions in the space provided.

1) In what ways did your instruction benefit from the use of personal response clickers, if any?

2) In what ways do you think the trainees benefited from the use of response clickers, if any?

3) If you continue using this format of instruction, what changes would you make, if any? 


\section{Biographies}

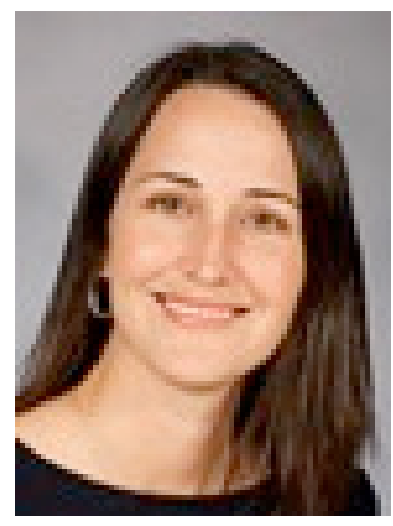

Dr. Angelina Hill is the Director of Institutional Research at the College of the Redwoods in Eureka, California. She was the Associate Director of Academic Assessment at the University of Nevada, Las Vegas. She earned a Ph.D. in Cognitive Psychology form the University of Notre Dame. Her research on perceptual learning and organization has been published in Perception \& Psychophysics, Perception, and Acta Psychologica. She was a research analyst for the project "Blended Learning Ecologies in the Military: Effectiveness of Enhanced Combat Lifesaver Training" awarded to the UNLV Division for Educational Outreach.

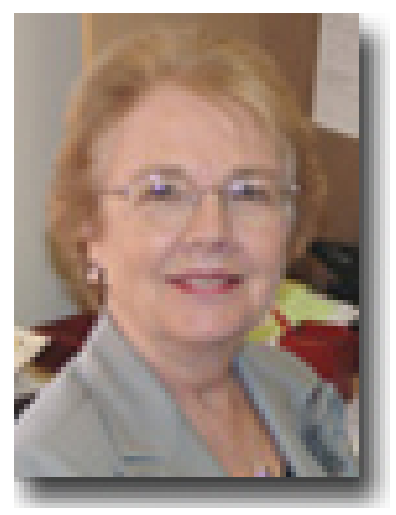

Dr. Bea Babbitt is an expert in higher education assessment and curriculum design, learning and math disabilities, and blended learning ecologies. She has taught and conducted research in these areas throughout her career. She has been a faculty member in the Department of Special Education, with an emphasis in assistive technology for the past 23 years at the University of Nevada, Las Vegas. She developed many innovative educational offerings including an online Ed. S. program in assistive technology. She recently retired from directing the Office of Academic Assessment at UNLV during which time she was the Principal Investigator for the project "Blended Learning Ecologies in the Military: Effectiveness of Enhanced Combat Lifesaver Training" awarded to the UNLV Division for Educational Outreach. 